\title{
Gebeliği Sırasında Miyokard İnfarktüsü Geçiren Hastada Sezaryen İçin Anestezi Yönetimi
}

\section{Anesthesia Management for Cesarean in Patient with Myocardial Infarction in Pregnancy}

Gülçin Hacıbeyoğlư ${ }^{1}$,

Sule Arıcan ${ }^{1}$,

Emine Vural Yalçın' ${ }^{1}$

Aybars Tavlan ${ }^{1}$,

Sema Tuncer Uzun ${ }^{1}$

${ }^{1}$ Necmettin Erbakan Üniversitesi Meram Tıp

Fakültesi Anesteziyoloji ve Reanimasyon

Anabilim Dalı, Konya, Türkiye

Gelis Tarihi/Received: 07 Subat 2018

Kabul Tarihi/Accepted: 27 Mayıs 2018

Yazışma Adresi: Gülçin Hacıbeyoğlu, Necmettin Erbakan Üniversitesi Meram Tıp

Fakültesi Anesteziyoloji ve Reanimasyon

Anabilim Dalı, Konya, Türkiye

e-posta:drgulcin81@gmail.com

ORCID

Gülçin Hacıbeyoğlu

https://orcid.org/0000-0002-9438-3414

Şule Arıcan

https://orcid.org/0000-0002-8634-1150

Öz

Gebelikte kalp hastalığı varlığı anne ölümlerinin halen en önemli sebeplerinden biridir. Gebelik sürecinde akut koroner sendrom gelişme riski artar. Sezaryen ile doğum kalp hastalığı olan gebelerde uygun hemodinamik izlem ve yönetim sağlar. Kalp hastalığı olan gebede uygulanacak ideal anestezi yöntemi ise tartışmalıdır. Rejyonel anestezi genellikle tercih edilen yöntem olmasına rağmen bazı özel durumlarda genel anestezi uygulanabilir. Invaziv monitörizasyon genel anestezi uygulanan kalp hastalarında mortalite ve morbiditeyi azaltır. Opioid kullanımı cerrahi ve entübasyona stres cevabı azaltır. Opioidin doğumdan önce uygulanması gerekiyorsa remifentanil hızlı etki başlangıcı ve metabolizması ile tercih edilecek ajandır. Bu olguda, antikoagülan kullanımı nedeni ile rejyonel anestezinin kontrendike olduğu yüksek kardiyak riskli gebede genel anestezi deneyimimizi sunmayı amaçladık.

Anahtar Kelimeler: Akut koroner sendrom; gebelik; anestezi; genel; remifentanil

\section{Abstract}

The presence of cardiac disease in pregnancy is still one of the most important reason of maternal mortality. The possibility of acute coronary syndrome increases in pregnancy. Birth with caesarean section provides proper hemodynamic monitoring and management in parturients with cardiac disease. However the ideal anesthetic to be applied to parturient with cardiac disease is controversial. Although regional anesthesia is usually preferred method, general anesthesia may be applied in some special cases. Invasive monitoring reduces mortality and morbidity in cardiac patients undergoing general anesthesia. Opioid use reduces the stress response to surgery and intubation. If the use of opioid is required before birth, remifentanil is the ideal agent because of its rapid onset of action and metabolism. In this case, we aimed to present our general anesthesia experience on a parturient with high cardiac risk where regiona anesthesia is contraindicated because of the use of anticoagulation.

Keywords: Acute coronary syndrome; pregnancy; anesthesia; general; remifentani

Emine Vural Yalçın

https://orcid.org/0000-0002-7921-7071

Aybars Tavlan

https://orcid.org/0000-0002-6064-0179

Sema Tuncer Uzun

https://orcid.org/0000-0002-6205-1702

\section{GíRiş}

Kalp hastalıkları, gelişmiş ülkelerde maternal mortalitenin başlıca nedenidir. Gebelerde, konjenital kalp hastalıklarına edinilmiş hastalıklara oranla daha sık rastlanır. Ancak aort diseksiyonu, peripartum kardiyomiyopati ve akut koroner sendrom gibi edinilmiş hastalıklar daha yüksek maternal mortalite ile ilişkilidir (1). Akut koroner sendrom geçirme riski, gebelikte 3-4 kat fazladır. İleri anne yaşı, obezite ve medikal komorbiditeler gibi risk faktörlerinin prevalansındaki artış, gebelik sürecinde miyokard enfarktüsünü daha yaygın hale getirir (2). Kalp hastalığı olan gebelerde, anestezi yönetimi büyük önem taşır ve uygulanacak ideal yöntem halen tartışmalıdır. Bu olguda; çocukluk döneminde mitral valv replasmanı olmuş, gebeliğinin ilk trimestrinde miyokard infarktüsü geçirmiş ve konjestif kalp yetmezliği olan, elektif sezaryen operasyonu geçirecek gebede genel anestezi yönetimini sunmayı amaçladık.

\section{OLGU}

Daha önce mitral valv replasmanı geçiren 29 yaşında, $65 \mathrm{~kg}$ ağırlığında bayan hasta antikoagülan kullanımını bıraktığı için, gebeliğinin 14. haftasında

Atıf yapmak için: Hacıbeyoğlu G, Arıcan Ş, Yalçın EV, Tavlan A, Uzun ST. Gebeliği Sırasında Miyokard İnfarktüsü Geçiren Hastada Sezaryen İçin Anestezi Yönetimi. Selcuk Med J 2020;36(1): 54-58 
anterior miyokard infarktüsü geçiriyor ve sol ön inen koroner artere perkütan transluminal koroner anjioplasti yapılarak litik tedavi uygulanıyor. Hastaya 35. haftada elektif sezaryen operasyonu planlanıyor.

Hastanın fizik muayenesinde; bilateral pretibial +/+ ödem ve mitral odakta metalik kapak sesi haricinde özellik yoktu. Elektrokardiyogramda (EKG) sinüs taşikardisi (105/dk) ve 1. derece atriyoventriküler blok mevcuttu. Ekokardiyografide ejeksiyon fraksiyonu \% 36, pulmoner arter basıncı $35 \mathrm{mmHg}$ olarak ölçüldü. Sol ventrikül duvar hareket bozukluğu olan hastada mitral kapak konumunda fonksiyonel prostetik kapak izlendi. Kapağın maksimum gradiyenti $23 \mathrm{mmHg}$, ortalama gradiyenti $6 \mathrm{mmHg}$ idi. Düşük molekül ağırlıklı heparin (Clexane ${ }^{\circledR}$, Aventis Intercontinental, Fransa) 6000 anti-Xa IU 2x1 kullanan hastanın tedavisi kardiyoloji tarafından düzenlenerek, saatte $1000 U$ heparin (Nevparin®, Mustafa Nevzat, İstanbul, Türkiye) infüzyonu başlandı. Operasyondan 4 saat önce heparin infüzyonu kesildi. Laboratuar değerleri; İnternational Normalized Ratio (INR) 1.98, Aktive Parsiyel Tromboplastin Zamanı (APTT) 38.3 saniye, hemoglobin $11 \mathrm{~g} / \mathrm{dl}$ ve diğer rutinleri normal olarak saptandı. Goldman kardiyak risk indeksi 20 puan olan hasta kardiyolojik açıdan yüksek risk ile elektif sezaryen operasyonuna alındı. Antikoagülan tedavi alan hastaya, hemodinamik açıdan da güvenli olacağı düşünülerek, genel anestezi verilmesi planlandı. Aydınlatılmış onam formu imzalatılarak, gerek duyulması halinde verilmek üzere taze donmuş plazma ve eritrosit süspansiyonu temin edildi. Hastaya rutin monitörizasyon (EKG, pulse oksimetre, noninvaziv kan basıncı) haricinde invaziv kan basıncı ve periferik sinir stimülatörü (TOFWatch ${ }^{\circledR}$ S,Organon, Dublin, İrlanda) ile kas gücü monitörizasyonu yapılması planlandı. 20 gauge intraket kullanılarak periferik bir damar yolu açıldı ve dengeli kristaloid çözeltisi infüzyonuna başlandı. Anestezi indüksiyonu öncesinde, hastanın sağ radial arter trasesine lokal anestezi uygulanarak, 20 gauge intraket ile invaziv arter monitorizasyonu yapıldı. Hasta indüksiyon öncesi \% 100 oksijen ile 3 dakika preoksijenize edildi. Eş zamanlı $0.5 \mathrm{mcg} /$ kg remifentanil (Rentanil $\circledast$, VEM, Ankara, Turkey) 5 dakikada infüze edildi ve $0.1 \mathrm{mcg} / \mathrm{kg} / \mathrm{dk}$ dozda infüzyona devam edildi. İndüksiyonda invaziv arter basıncı takip edilerek kirpik refleksi kaybolana kadar toplam $120 \mathrm{mg}$ propofol (Propofol \%1 Fresenius $\circledR$, Fresenius Kabi AB, Uppsala, İsveç) yapıldı. Daha sonra hastaya $1 \mathrm{mg} / \mathrm{kg}$ dozda rokuronyum (Myocron $\circledast$, VEM, Ankara, Türkiye) yapılarak hızlı sıralı indüksiyon

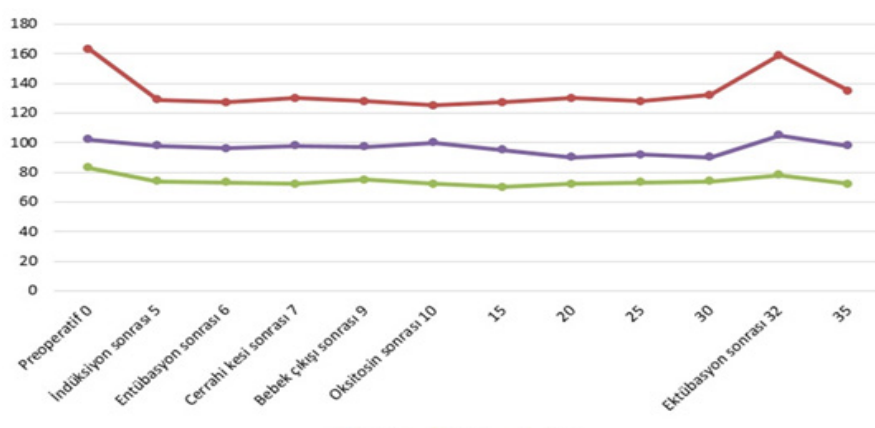

SAB: Sistolik Arter Basıncı, DAB: Diastolik Arter Basıncı, KAH: Kalp Atım $\mathrm{H} \mid \mathrm{ZI}$

Şekil 1. Operasyon süresince hastanın hemodinamik parametre değişiklikleri

uygulandı. Hasta 40. saniyede train of four (TOF) \% 0 iken video laringoskop kullanılarak sorunsuz entübe edildi. Anestezi idamesinde atoni riskini azaltmak için düşük minimum alveoler konsantrasyonda (0.5 MAC) sevoflurane (Sevorane $\AA$, Aesica Queenborough Ltd. Oueenborough Kent ME11 5EL, İngiltere) ile remifentanil kullanılarak hemodinamik stabilite sağlandı. Cerrahi kesiden 2 dakika sonra bebek çıkarıldı ve remifentanil infüzyon dozu $0.2 \mathrm{mcg} / \mathrm{kg} /$ dk doza yükseltildi. Bebeğin Apgar skoru 1.dakikada 6, 5. dakikada 9 olarak değerlendirildi. Plasenta çıkarıldıktan sonra hastaya 10 ünite oksitosin (Synpitan®, Deva Holding A.Ş., Tekirdağ, Türkiye) intravenöz (ıv) yavaş puşe yapıldı. Operasyon süresince hastaya $800 \mathrm{ml}$ kristaloid verildi, $100 \mathrm{ml}$ idrar çıkışı oldu ve hemodinamik parametreleri normal sınırlarda seyretti (Şekil 1). Postoperatif analjezi amacı ile $150 \mathrm{mg}$ tramadol (Tradolex®, Mefar İlaç, İstanbul, Türkiye) ve $3 \mathrm{mg}$ morfin (Morphine $\mathrm{HCl}$, İdol İlaç, İstanbul, Türkiye), antiemetik olarak 4 mg ondansetron (Zofran®), GlaxoSmithKline, Research Triangle Park, İngiltere) IV yavaş puşe ile yapıldı. Otuz iki dakika süren operasyonda transfüzyon intiyacı olmadı ve vaka sonunda TOF \% 0 ölçülen hastaya Iv $4 \mathrm{mg} / \mathrm{kg}$ sugammadeks (Bridion $®$, Patheon Manufacturing Services, North Carolina, USA) yapıldı. İki dakika sonra TOF \% 90 ölçüldü ve hasta ekstübe edildi. Vizüel analog skala (VAS) skoru 3 olan hasta, postoperatif kalp fonksiyonlarının yakın takibi için yoğun bakıma alındı ve 24 saat sonra herhangi bir komplikasyon gelişmemesi üzerine servise devredildi. Postoperatif dönemdeki analjezisi Iv morfin PCA (1 $\mathrm{mg} / \mathrm{ml}$ dozda morfin, her bolusta $1 \mathrm{ml}$, lock-out süresi 6 dakika ) kullanılarak sağlandı. Postoperatif 4. günde anne ve bebek sorunsuz bir şekilde taburcu edildi. 


\section{TARTIŞMA}

Gebelik, doğum ve postpartum dönemdeki hemodinamik değişiklikler kalp hastalarında kardiyak dekompansasyona zemin hazırlar. Yüksek kardiyak riskli gebelerde sezaryenle doğum, özellikle hemodinamik değişiklikleri ortadan kaldırarak daha kontrollü bir izlem ve yönetim sağlar (3). Bu hastalarda peripartum dönemde, diastolik basıncın düşmesi, kalp atım hızının artması ve hipertansiyon gelişmesi koroner beslenme açısından risk oluşturur. Bu nedenle kalp hastalığı olan gebede anestezi hedefleri; anneyi ve bebeği koruyarak havayolunu güvence altına almak, anestezi ve cerrahiye bağlı gelişebilecek hemodinamik değişiklikleri önlemek, miyokardın iş yükünü artırmamak, mevcut kalp yetmezliğini dekompanse hale getirmemek, yeni bir koroner iskemiye neden olmamak ve etkin bir postoperatif analjezi sağlamak olmalıdır. Kalp hastalığı olan gebelerde oluşabilecek kardiyovasküler stres, kullanılan medikasyonlar özellikle de antikoagülan kullanımı anestezi yönetimini etkiler. Rejyonel anesteziye bağlı gelişen hipotansiyon ve bradikardinin tedavisinde kullanılan sıvılar ve vazopressörler kalp rezervi sınırlı olan hastalarda sorun oluşturabilir. Genel anestezi ise kardiyovasküler instabilite gelişimi, zor havayolu ve mide içeriğinin aspirasyonu gibi riskler içerir (4). Obstetrik anestezide maternal mortaliteyi azalttığı için önerilen yöntem rejyonel anestezidir. Ancak bazı özel durumlarda genel anestezi de uygulanabilir. Olguda genel anestezi tercih edilmesinin sebebi antikoagülan kullanımına bağlı INR yüksekliğidir.

Genel anestezi uygulanacak kalp hastalarında uygun invaziv monitörizasyonun mortalite ve morbiditeyi azalttığı gösterilmiştir (5). İnvaziv arter monitörizasyonu ile anestezi süresince anlık hemodinamik takip yapılabilir. Kalp fonksiyonlarını değerlendirmek için transtorasik ve transözofageal ekokardiyografi, pulmoner arteriyel kateterizasyon, CVP (santral venöz basınç) ve PPV (pulse pressure variation) gibi invaziv ve non-invaziv yöntemler kullanılabilir. Günümüzde, gebelerde uygulanan anestezik yöntemin kardiyak etkilerini ölçmek için non-invaziv kardiyak output monitörizasyonları da kullanılmaktadır (6). Non-invaziv kardiyak output ölçümünde kullanılan dinamik değişkenlerin volüm durumunundeğerlendirilmesindestatikgöstergelerden daha üstün olduğu gösterilmiştir (7). Hemodinamik monitörizasyonun yanında bu hastalarda anestezi derinliğinin takip edilmesi de önemlidir. İnhalasyon ajanları hem yenidoğanda depresif etkileri azaltmak hem de uterin kas tonusunu koruyarak postpartum kan kaybını azaltmak için düşük MAC ile kullanılır. Ancak bu kullanım şekli anestezide farkındalık riskini artırmaktadır. Bispektral index monitörizasyonu (BIS) uygun anestezi derinliği sağlamaya yardımcı olarak anestezide farkındalığı önlemektedir (8). Bu olguda invaziv monitörizasyon yöntemlerini antikoagülan kullanım öyküsü nedeniyle ve major kan kaybı beklemediğimiz için tercih etmedik. Non-invaziv ölçüm metodlarını ve BIS monitörizasyonunu ise teknik yetersizlikler nedeniyle kullanamadık. Hastanın volüm ihtiyacına intraoperatif kan kaybı ve idrar çıkışını takip ederek karar verdik. Ayrıca indüksiyon öncesi invaziv arter monitörizasyonu yaparak hemodinamik cevabı anlık izleyip müdahale edebildik. Genel anestezide kullanılan sistemik opioidlerin cerrahiye stres cevabı baskıladığı gösterilmiştir (9). Bununla birlikte neonatal depresyon riskini önlemek için sezaryende genellikle opioid uygulamasından doğuma kadar kaçınılır. Remifentanil kısa yarı ömrüyle güçlü bir sentetik $\mu$-reseptör agonistidir (10). Opioidin doğumdan önce uygulanması gerekiyorsa remifentanil hızı etki başlangıcı ve hızlı metabolizması ile tercih edilecek ajandır. Gebelerde de hemodinamik stabiliteyi korumaya yardımcı olur (11). Remifentanilin farklı dozları geçici neonatal depresyona neden olmaktadır $(12,13)$. Ancak literatürde bizim kullandığımız dozlarda anne ve bebek açısından güvenle kullanılabileceğini gösteren bildirimler vardır $(14,15)$. Hastamızda, hemodinamik stabilitenin sağlanması son derece önemli olduğundan, indüksiyonda düşük doz remifentanil infüzyonunu tercih ettik. Bu sayede, hipnotik dozunu azaltarak indüksiyonda oluşabilecek hipotansiyonu önlemiş ve entübasyona hemodinamik cevabı baskılamış olduk. Neonatal açıdan ise geçici hafif bir depresyonla karşılaştık. Taktil uyarı ile spontan soluyan bebeğin 5 . dakika Apgar skoru ve klinik takipleri ise normaldi.

Gebelikte kilo alımı ve solunum yolları mukozasında ödem gelişimi, uterusun büyümesi, fonksiyonel rezidüel kapasitede azalma, artmış oksijen tüketimi ve daha kolay hipoksemi gelişimi havayolu yönetimi ile ilgili riskleri artırır. Bu nedenle gebelerde zor havayolu açısından daima hazırlıklı olunmalıdır. Video laringoskoplar zor ve başarısız entübasyon sorununu çözmek için geliştirilen, hızlı seri indüksiyonda entübasyonu kolaylaştıran ve gebelerde de potansiyel kullanımı giderek artan araçlardır (16). Video laringoskopların glottik görüntü kalitesini iyileştirdiği kesindir ancak laringoskopiye hemodinamik cevabı baskılamada üstünlükleri tartışmalıdır $(17,18)$. Yüksek kardiyak riskli bu gebede 
video laringoskop kullanmamızın hem entübasyona hemodinamik yanıtı baskılamak için hem de olası zor havayolu senaryosu için doğru bir seçim olduğunu düşünmekteyiz. Genel anestezi sonrası, yeterli kas gücünün geri kazanılması hasta güvenliği açısından önemlidir. Sezaryen için hızlı seri indüksiyon ve entübasyonda, $1 \mathrm{mg} / \mathrm{kg}$ rokuronyum ile süksinilkolinin benzer entübasyon koşulları sağladığı gösterilmiştir (19). Bu olguda rokuronyumu tercih etmemizin en önemli sebebi kas gücünü sugammadeks ile geri getirebilecek olmamızdı. Sugammadeksin gebelerde non-obstetrik cerrahide kullanımı ile ilgili yeterli bilgi yokken, ciddi kas hastalığı veya kalp hastalığı olan gebelerin sezaryen anestezisinde güvenle kullanılabileceği bildirilmiştir (20-23). Biz de kalp hastası olan gebede sugammadeks kullanarak güvenli, hızlı ve konforlu bir ekstübasyon süreci sağlamış olduk. Postoperatif dönemde miyokardın iş yükünü artırabilecek en önemli stres kaynağı ağrıdır. Bu nedenle postoperatif analjezi yönetimi çok önemlidir. Bu olguda antikoagülan kullanımı nedeniyle santral blokları ve gövde bloklarını uygulayamadık. Kalp yetmezliği de olan hastada olası böbrek hasarı oluşturmamak ve koagülasyonu etkilememek için non-steroidal antiinflamatuar ilaç tercih etmedik. Etkin analjezi sağlayabilmek için intraoperatif iki farklı opioidin additif etkisinden faydalandık ve Iv PCA ile analjezi yönetimine devam ettik.

Sonuç olarak kalp hastalığı olan gebede uygulanacak ideal anestezi yöntemi halen tartışmalıdır. Perioperatif dönemde miyokardın iş yükünü artırabilecek değişiklikleri engellemek ana hedef olmalıdır. Genel anestezi uygulanacak hastalarda, remifentanil gibi güçlü bir opioidin doğru monitörizasyon eşliğinde kullanılması, hemodinamik stabiliteyi sağlamak açısından faydalı olabilir.

Çıkar Çatışması: Çalışmada herhangi bir çıkar çatışması yoktur.

Finansal Çıkar Çatışması: Çalışmada herhangi bir finansal çıkar çatışması yoktur.

Yazışma Adresi: Gülçin Hacıbeyoğlu, Yunus Emre Mahallesi Necmettin Erbakan Üniversitesi Meram Tıp Fakültesi Anesteziyoloji ve Reanimasyon Anabilim Dalı, 42080 Meram/ Konya, Türkiye

Telefon: 05054455498

e-posta: drgulcin81@gmail.com

\section{KAYNAKLAR}

1. Khairy $\mathrm{P}$, Ionescu-Ittu $\mathrm{R}$, Mackie AS, et al. Changing mortality in congenital heart disease. J Am Coll Cardiol 2010;56(14):1149-57.

2. Callaghan WM, Creanga AA, Kuklina EV. Severe maternal morbidity among delivery and postpartum hospitalizations in the United States. Obstet Gynecol 2012;120(5):1029-36.

3. Deneux-Tharaux C, Carmona E, Bouvier-Colle $\mathrm{MH}$, et al. Postpartum maternal mortality and cesarean delivery. Obstet Gynecol 2006;108:541-8.

4. Şahin Ş. Obstetrik anestezi ve analjezi. Tüzüner $F$, ed. Anestezi Yoğun Bakım Ağrı, 1. Baskı. Nobel Tıp Kitabevi, İstanbul, 2010:973-1008.

5. Bonnin M, Mercier FJ, Sitbon O, et al. Severe pulmonary hypertension during pregnancy mode of delivery and anesthetic management of 15 consecutive cases. Anesthesiology 2005;102(6):1133-7.

6. Orbach-Zinger S, Bizman I, Firman S, et al. Perioperative noninvasive cardiac output monitoring in parturients undergoing cesarean delivery with spinal anesthesia and prophylactic phenylephrine drip: A prospective observational cohort study. J Matern Fetal Neonatal Med 2018; 22:1-7.

7. Marik PE, Cavallazzi R, Vasu T, et al. Dynamic changes in arterial waveform derived variables and fluid responsiveness in mechanically ventilated patients: A systematic review of the literature. Crit Care Med 2009;37(9):2642-7.

8. Avidan MS, Zhang L, Burnside BA, et al. Anesthesia awareness and the bispectral index. $N$ Engl $J$ Med 2008;358:1097-108.

9. O'Hare R, McAtamney D, Mirakhur RK, et al. Bolus dose remifentanil for control of haemodynamic response to tracheal intubation during rapid sequence induction of anaesthesia. Br J Anaesth 1999;82(2):283-5.

10. Glass PS, Hardman D, Kamiyama Y, et al. Preliminary pharmacokinetics and pharmacodynamics of an ultrashort-acting opioid: Remifentanil (GI87084B). Anesth Analg 1993;77:1031-40.

11. Yoo KY, Kang DH, Jeong $H$, et al. A dose-response study of remifentanil for attenuation of the hypertensive response to laryngoscopy and tracheal intubation in severely preeclamptic women undergoing caesarean delivery under general anaesthesia. International J Obs Anesthesia 2013;22(1):1018.

12. Park BY, Jeong CW, Jang EA, et al. Dose-related attenuation of cardiovascular responses to tracheal intubation by intravenous remifentanil bolus in severe pre-eclamptic patients undergoing caesarean delivery. British J Anaesthesia 2011;106(1):82-7.

13. Noskova P, Blaha J, Bakhouche $\mathrm{H}$, et al. Neonatal effect of remifentanil in general anaesthesia for caesarean section: $A$ randomized trial. BMC Anesthesiology 2015;15:38.

14. Sağır Ö, Özgül Ü, Köroğlu A. Sezaryen yapılacak multipl sklerozlu gebede anestezi uygulaması. Turkiye Klinikleri J Anest Reanim 2011;9(1):61-5.

15. Alexander R, Fardell $S$. Use of remifentanil for tracheal intubation for caesarean section in a patient with suxamethonium apnoea. Anaesthesia 2005;60(10):1036-8.

16. Scott-Brown S, Russell R. Video laryngoscopes and the obstetric airway. International Journal of Obstetric Anesthesia 2015;24(2):137-46.

17. Sarkılar G, Sargın M, Sarıtaş TB, et al. Hemodynamic responses to endotracheal intubation performed with video and direct laryngoscopy in patients scheduled for major cardiac surgery. Int J Clin Exp Med 2015;8(7):11477-83.

18. Maassen RL, Pieters BM, Maathuis B, et al. Endotracheal intubation using video laryngoscopy causes less cardiovascular response compared to classic direct 
laryngoscopy, in cardiac patients according a standard hospital protocol. Acta Anaesthesiol Belg 2012;63(4):181-6.

19. Abu-Halaweh SA, Massad IM, Abu-Ali HM, et al. Rapid sequence induction and intubation with $1 \mathrm{mg} / \mathrm{kg}$ rocuronium bromide in cesarean section, comparison with suxamethonium. Saudi Med J 2007;28(9):1393-6.

20. Stourac P, Krikava I, Seidlova J, et al. Sugammadex in a parturient with myotonic dystrophy. $\mathrm{Br} \mathrm{J}$ Anaesth 2013;110(4):657-8.
21. Varela N, Lobato F. Sugammadex and pregnancy, is it safe?. J Clin Anesth 2015;27(2):183-4.

22. Soyoral L, Goktas U, Cegin MB, et al. Successful use of sugammadex for caesarean section in a patient with myasthenia gravis. Rev Bras Anestesiol 2017;67(2):221-2.

23. Sengul T, Saracoglu A, Sener S, Bezen O. The use of sugammadex in a pregnant patient with Wolff-ParkinsonWhite syndrome. J Clin Anesth 2016;33:1-4. 